\title{
Fernan Díaz, quem teve que esperar 800 anos para se casar, ou: Sobre desleituras históricas e revisões canônicas
}

\section{Resumo:}

Entre o acervo jacente nas cantigas de escárnio e mal-dizer contam-se várias de teor homoerótico, via de regra marcadas pela chacota e/ou pelo denosto. Alguns personagens do mundo medieval são focalizados em várias cantigas, de vários trovadores. A de 1479 do Cancioneiro da Biblioteca Nacional, de autoria de Airas Pérez Vuitoron, trata de um certo Fernan Díaz, provável meirinho real, que parece alimentar ilusões de casar-se com alguém de seu sexo, para escárnio geral. É comentada, assim como as referidas, na imprescindível edição do cancioneiro escarninho feita por Rodrigues Lapa (1965). Ao redor desse desejo e das reações que gera, em termos de desleitura desse tópico quando se trata do ensino da literatura dos cancioneiros, o presente texto adota um olhar crítico sobre a necessidade de remontagem, de releitura do deslido, do cânone literário da língua portuguesa, sob o princípio de que construção de memória equivale à construção de cidadania.

\section{Palavras-chave:}

Cancioneiro de Escárnio e Maldizer, Homoerotismo na Idade Média, cânone literário

\section{Abstract:}

There are many poems of homoerotic bias/themes amongst the archive of the "cantigas de escárnio e maldizer", which in general show traces of satire and/or disgust. Some characters of medieval Portugal are focussed in series of such cantigas, composed by many Gallician and Portuguese troubadours. Cantiga 1479, collected at the Cancioneiro da Biblioteca Nacional is by Aires Pérez Vuitoron and deals with some Fernan Días, who probably was a royal justice, who seems to have developed delusions of marrying someone of his own gender -to general scorn. It is studied in the fundamental edition of the "Cancioneiro Escarninho" (i.e., "Scornful Poetry Collection") organized by Rodrigues Lapa (1965). The present essay adopts a critical eye on the necessity of reshaping and re-reading the unread in the literary canon of the Portuguese language. Such a critical stance considers that the construction of memory -including the literary one- coincides with the construction of citizenry.

Keywords:

Gallician-Portuguese Satirical Cancioneros, Homoeroticism in the Middle Ages, literary canon 
Começo este texto direto com a transcrição de uma cantiga, que corresponde ao número 1479 do Cancioneiro da Biblioteca Nacional, e que cito da imprescindível edição das Cantigas d'escarnho e mal dizer dos cancioneiros medievais galego-portugueses de Manuel Rodrigues Lapa, ${ }^{1}$ que seguirei de perto:

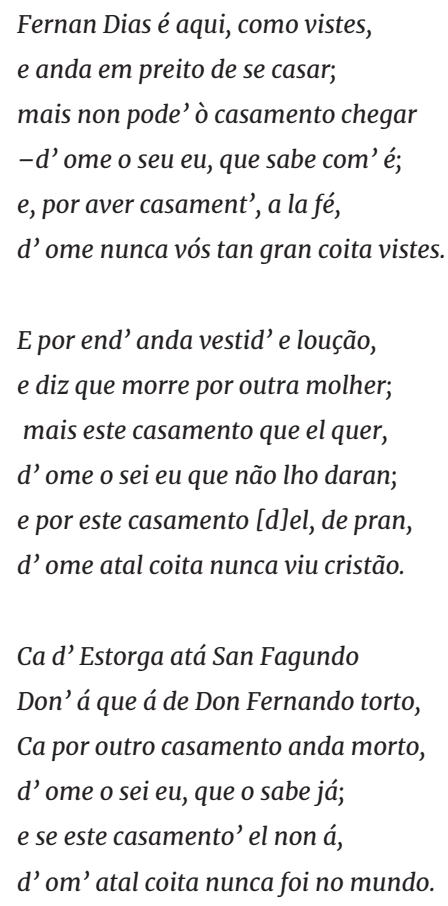

O autor desta pequena jóia de nossa memória escarninha foi o trovador galego Airas Pérez Vuitoron, ativo em terras lusas entre 1246 e 1253, como membro dos homens de armas que acompanharam o infante D. Afonso de Castela na ajuda que este prestou a D. Sancho II para manter-se no trono, conforme se lê no Dicionário da literatura medieval galega e portuguesa. ${ }^{2}$ Falamos pois de priscas eras, do período formativo do português enquanto língua e língua literária, portanto ainda umbilicalmente ligado ao galego, da qual se origina.

Falamos, outrossim, de um trovador guerreiro bem-sucedido, beneficiado que foi no Repartimento de Sevilha, em cuja conquista terá tido papel preponderante (1248), e de sua forma de ver o mundo e interagir com os seus contemporâneos através da poesia. Ainda, falamos de textos produzidos há oito séculos, e que podem - devem - ser lidos em nossos dias como se atuais. Para muitos leitores contemporâneos, tal espelhamento distante torna-se difícil devido à sua legibilidade. $O$ papel da disciplina filológica outro não é senão este: torná-los, na medida do possível, transparentes aos nossos olhos, reunindo-nos com o passado. Nesse sentido, vamos ao poema, guiados por Rodrigues Lapa. 
Um certo Fernan Díaz - figurinha carimbada nesses tempos, sobre quem voltaremos mais adiante - "anda em preito de se casar" - ou seja, pretende contrair matrimônio -, e tem "coita", isto é, pressa, e nunca ninguém viu tanta pressa assim ("a la fé,/ d' ome nunca vós tan gran coita vistes"). ${ }^{3}$ Chegamos ao final do sentido da primeira estrofe. No primeiro verso da segunda estrofe, ficamos sabendo que Fernan Díaz "anda vestid' e loução" - isto é: tem cuidado, excessivo talvez, com sua aparência e trajes - e "diz que morre por outra molher" (quem seria esta "outra", de uma primeira que não se tem notícia? quiçá o mesmo personagem, de tal sorte feminizado?); porém, frisa maledicente o poeta, "mais o casamento que el quer,/ d'ome o sei eu que não lho daran", porque "este casamento [d]el, de pran,/ d' ome atal coita nunca viu cristão."

Que tipo de enlace seria, então, este, que ninguém vira antes, e que vedado lhe é? Não parece ser do tipo de relação de "irmandamento", adelphopoiesis, ou seja, de contrato de amizade, socorro mútuo, fraternidade e, muitas vezes, coabitação entre dois homens que em certas regiões da cristandade, nomeadamente o orbe ortodoxo, era celebrado por oficiantes e tinha valor religioso semelhante ao do matrimônio heterossexual.4 Sobre esta modalidade de relacionamento masculino, há duas correntes de interpretação: uma, feita por historiadores da religião, que interpretam os textos de diversas fontes sobre o tema enquanto santificadores de um vínculo assexuado do tipo o de Jônatas com Davi no Antigo Testamento, e outra, de revisão desta postura, construída pelo historiador americano John Boswell em seus particularmente espicaçantes estudos Same-Sex Unions in Pre-Modern Europe e Christianity, Social Sciences and Homosexuality, 5 em que supõe que o vínculo criado por tais cerimônias incluía um componente de relacionamento sexual entre tais "irmãos". Ou seja, menos "bromance" e mais, digamos, casamento igualitário, com todos os seus qüiproquós. Na região que contemplamos neste estudo, o norte de Portugal e a Galícia, há pelo menos um "irmandamento": entre Pedro Díaz e Muño Vandilaz, registrado no tombo de Celanova (região de Ourense, fronteira de Portugal), no ano de 1061 -antes, portanto, da existência autônoma do país luso (1139). ${ }^{6}$ Como teria sido a relação entre esses galego-portugueses? Quantos documentos haverá que obedeçam o princípio expressado no Evangelho de Mateus, que aqui sito em galego: "Pois ben, o que Deus uniu non o separa o home" (Mateus, cap. 19)? Não podemos responder a tais perguntas, embora não deixe de fascinar-nos a deriva imaginária que possibilitam.

Regressemos pois à cantiga, posto que nela tudo indica que o tipo de casamento que Fernan Díaz almeja inclui a economia sexual com um indivíduo de seu sexo. As vozes da maledicência são conjuradas no começo da terceira e última estrofe: "Ca - i.e., pois - d'Estorga atá San Fagundo", portanto, do Reino de Leão à Galícia, "há mais de uma dona que se queixa por ele preferir casamento de homens", na interpretação de Rodrigues Lapa dos versos "don' á que á de Don Fernando torto,/ ca por outro casamento anda morto" (i.e., ansioso). Termina a cantiga "e se este casament' el non á, / d' om atal coita nunca foi no mundo" - ou seja, nunca houve ninguém tão apressado como Fernan Díaz para... Casar-se com alguém do seu sexo.

Em seu comentário ao significado geral do poema, o filólogo declara: "Cantiga um pouco sibilina. $\mathrm{O}$ autor parece insinuar que Fernão Dias era um homossexual, pela propositada equi- 
Cadernos de Literatura Comparada

Fernan Díaz, quem teve que esperar 800 anos para se casar

vocação que estabelece, para além da pontuação, quando nos fala em 'casamento/ de homens'. Aliás, Vuitoron era inclinado a estes jogos verbais e as referencias à pederastia são freqüentes nele." 7 A cantiga subseqüente (81), também trata da mesma personagem e do mesmo tema: nela o trovador caçoa de nosso adamado antecessor que fora "promovido agora a um posto importante da administração. Ainda aqui - diz Rodrigues Lapa - pelo propositado equívoco de expressões como ir atrás e ir adeante (sic), parecem insinuar-se vícios de pederastia" (ibidem). Díaz não foi o único homossexual ridicularizado por Vuitoron: tampouco um certo Estevão Anes, também alto funcionário real, que vivia em concubinato com um seu vilão (73) não escapa do denosto do poeta. Mas Fernan Díaz é quem parece ter sido a "Geni viada" de sua época: além de Vuitoron, vários trovadores dedicaram-lhe composições de escárnio. No verbete dedicado ao poeta no Dicionário assinalado, mencionam-se sobre ele cantigas de Pêro Garcia Burgalês, Estevan Faian, Vasco Pérez Pardal e Pêro da Ponte. É na cantiga de Burgalês (379) que a profissão de Fernan Díaz se esclarece: era meirinho - i.e., um cargo de confiança do sistema de justiça real - de D. Afonso X de Castela, suserano de Vuitoron e provavelmente da maior parte desses trovadores.

Ou seja, um homossexual femme e com poder, protegido pelo Rei apodado El Sabio quem foi, como sabemos, um renomado trovador que preferia trovar em galego-português e compôs muitas excelentes cantigas de amor, amigo e escárnio e mal dizer. Aos reis práticos, pouco lhes importa o que com seus corpos façam os seus funcionários desde que estes de fato funcionem: Fernán Díaz deve ter sido bom no seu régio métier, haja visto que sua notoriedade pública talvez tenha pesado mais do que sua sexualidade como fonte de inspiração a tanto escárnio e mal dizer. Contudo, de nada lhe valeram seus atributos, conhecimentos, altas relações: para o nosso cancioneiro entra vilipendiado devido à sua evidente homossexualidade e ... ao seu então tido e havido como ridículo, inaudito desejo de casar-se - casar-se, não "irmandar-se" - com alguém de seu sexo. Na Espanha, o casamento igualitário data de 2005 e em Portugal, de 2010. Aqui no Brasil podemos casar-nos desde 2013, graças a um parecer dos atuais "meirinhos" do Supremo Tribunal Federal. Se Fernan Díaz nos representa na Idade Média ibérica, portanto há viados pensando nisso, e tendo esse seu pensar percepção pública sob a indigitação de escândalo, em nosso orbe cultural desde 1240 mais ou menos. Pobre Fernan Díaz, quem teve que esperar 800 anos para se casar.

Há muito a tecer de tudo isto, mas fiquemos por enquanto com um mínimo indiscutível de informações: a problemática homoerótica está presente na literatura de nossa língua desde a sua fundação enquanto sistema literário. Sem embargo disso, nela não se fala. O tema é silenciamento censor, secular. De longe, o valor didático da lírica medieval recai nas cantigas de amor e de amigo. Para começo de conversa, e via de regra, pouco se ensinam as cantigas de escárnio e maldizer. A censura começa aí: na desleitura que divide a origem cronológica real do cânone, i.e., o nosso cancioneiro, entre discursos tradicionalmente tidos como "elevados", nobres, espirituais, contra os considerados "baixos", chãos, vilãos, focalizados estes, freqüentemente, e quando o são, em posição de subalternidade. Um exemplo? o fato de Rodrigues Lapa ter tido que publicar a primeira edição do livro que nos ocupa na Galícia - em Vigo, Ediciones Galaxia, 1965 - porque 
o salazarismo tinha censurado o seu aparecimento em Portugal.

A questão do cancioneiro escarninho é particularmente importante porque em Portugal não existem narrativas medievais como os Canterbury Tales de Chaucer ou o Decameron de Boccaccio. ${ }^{8}$ Para se ter uma ideia mais completa da humanidade portuguesa durante a Idade Média, o estudioso deve considerar não apenas os cronistas, eivados de espírito áulico até o surgimento das crônicas de Fernão Lopes, como também os trovadores na pluralidade de suas criações, sob pena de transformar homens e mulheres de carne e osso em algo idealizado e distante. A humanidade que ressuma do cancioneiro escarninho, em nossa tradição, compensa a falta de narrativas bem-humoradas e realistas como as de Chaucer e Boccaccio, que retratem não apenas o ambiente cortesão como o das praças, no sentido das noções gêmeas de carnavalização e paródia desenvolvidos por Mikhail Bakhtin em Rabelais and his times (escrito em 1940, censurado e finalmente publicado em 1965 em Moscou).

Assim, o pensamento canônico elidiu - desleu - pouco a pouco toda uma corrente de textos do racconto da memória literária portuguesa, postura esta herdada por aqueles que conformaram o cânone brasileiro. Aqui está a origem da oficialização daninha de nossa tradição. Cantigas de Escárnio e Mal Dizer mal estudadas e das quais se subtraem tópicos considerados incômodos como o da que analisamos, correspondem diretamente à "higienização" da memória literária enquanto construção de mitos nacionais em Portugal e no Brasil, tais como os da "democracia racial" e do "homem cordial" aqui e o da "terra de brandos costumes" e o "orgulhosamente sós" lá, para a consecução de discursos oficiais que perduram até hoje.

Nesse sentido, renovar o cânone literário é essencial para democratizar o passado. Desler a desleitura. Obliterá-la. Obliterá-la em sala de aula. Consciente, ideológica e repetidamente. Consideremos ainda que obras de autores centrais do cânone também sofreram este princípio de apagamento censório. Nem mais nem menos do que o vate por antonomásia de nosso sistema literário, Luís de Camões, apenas em tempos mais recentes tem merecido um olhar inquisitivo sobre composições suas nas quais se evidenciam temas e imagens homoeróticas. ${ }^{9}$ E tantos outros, que conformaram o cânone com suas obras mas que não previram o suave processamos censor de desleitura aos quais seus pósteros as submeteriam, sob as bênçãos das grandes instituições do Estado e da Cultura, entre as quais muito particularmente a Academia. Por outro lado, a inexistência de antologias compreensivas de poesia homossexual em português, que reunissem autores de ambos os lados do Atlântico, inclusive os de países africanos de expressão portuguesa, é, em si, de lamentar-se, principalmente se levarmos em conta que, por exemplo, a primeira edição da The Columbia Anthology of Gay Literature - Readings from Western Antiquity to the Present Day, editada por Byrne R.S. Fone, é de 1998, ao passo que a primeira antologia local - Poesia gay brasileira, editada por Amanda Machado e Marina Moura - apareceu somente em 2018. A presença de autores de língua portuguesa nas grandes antologias de literatura homossexual é restrita, e menos se consideramos as primeiras obras do gênero. Em Calamus - Male Homosexuality in Twentieth Century Literature - An International Anthology (1982) e no The Penguin Book of Homosexual Verse (1983), célebres por terem "esquentado" o mercado editorial pink-oriented, antes das grandes antologias como a anteriormente mencionada, estão, 
Cadernos de Literatura Comparada

Fernan Díaz, quem teve que esperar 800 anos para se casar

respectivamente, um conto de Darcy Penteado - "The Ice-Cream Fairy" ("A bichinha sorveteira") - e um poema de Cassiano Nunes, "Episode" ("Episódio")..$^{10}$ Mais nada nem ninguém de expressão portuguesa. Ora, quem não produz antologias que tais em casa termina por não entrar nas antologias feitas fora dela. Certo?

Aqui, grandes editoras comerciais eternizam suas etéreas promessas de levar a cabo alguma coleção ambiciosa da lírica homoerótica, principalmente a produzida na língua portuguesa, enquanto as universitárias, pois, olham para o outro lado, estruturadas como são por conselhos editoriais formados por sumidades acadêmicas que não reconhecem tal urgência - mesmo porque, talvez, muitas delas habitem seus muito silenciosos, confortáveis e sequinhos armários e não querem bulir no vespeiro.

Frise-se que na montagem tradicional do cânone literário em português, não apenas a temática homoerótica foi rasurada. No terreno da sexualidade, citemos por exemplo a Antologia de poesia portuguesa erótica e satírica, selecionada, prefaciada e anotada pela poeta Natália Correia, que cobre dos cancioneiros à segunda metade do século vinte, e que, assim como a obra de Rodrigues Lapa que estudamos, foi censurada pelo salazarismo quando de sua primeira edição, no mesmo ano de 1965. Desde essa primeira - a terceira e mais recente edição é de 1999 -, o poeta português David Mourão Ferreira pergunta retoricamente em uma nota nela aditada: "Como é possível que uma Antologia como esta ainda não tivesse sido realizada?"

Pois, não o tinha sido até então e não voltou a sê-lo depois, ou se, apenas timidamente, e já lá vão 55 anos. Natália Correia esclarece em seu prefácio o que lhe motivara a levar a cabo seu projeto:

Normalizar o que uma civilização empecida pelo remorso desfrutou envergonhadamente no irresistível gozo do proibido, desprestigiar a fascinação do mal, fazendo explodir a carga de sua concomitante angústia, trazer as recalcadas supurações do instinto, desinibindo-as da compreensão estimulante dos tabus, eis o que parece ser o canal de uma estabilização psicológica apaziguadora. ${ }^{11}$

Nada a discordar em tal desiderato. Mesmo porque não pode haver estabilidade psicológica em sociedades não normalizadas pelo direito e pela igualdade na busca de sua expressão e do reconhecimento público desta, que é uma das formas da busca da felicidade à que grupos sociais, como os de Fernan Díaz e o das autoras de língua portuguesa tiveram acesso denegado.

Generosa, porém não surpreendentemente, Natália Correia dedica à filóloga teuto-portuguesa D. Carolina Michaëlis de Vasconcelos a sua antologia. ${ }^{12}$ D. Carolina foi quem, no pudibundo século XIX, primeiro arriscou a ler sem desler o cancioneiro escarninho. Rodrigues Lapa também assinala o labor da "insigne romanista", quem "com coragem meritória e abnegado espírito científico" publicou uma coleção de "Notas marginais aos velhos Cancioneiros" na Alemanha, ${ }^{13}$ opondo-se ao silenciamento do núcleo filológico patriarcal que os processara desde o começo da centúria.

Neste sentido, não quero terminar o presente texto sem agradecer a esta linhagem de mulheres indômitas a sua pouco valorizada contribuição, no heterocêntrico e machista sistema li- 
terário que há séculos predomina na formação do cânone da literatura em português, em função de uma finalidade que temos em comum: a renovação do cânone literário, o desmascaramento da desleitura secular que nos conforma desde a nossa escolarização enquanto leitores do arquivo da língua que compartilhamos. Reler o deslido sempre significará incluir as vozes femininas que ficaram no passado e pouco ecoam no racconto que temos por compromisso ético de fazer chegar aos estudantes e a todos aqueles que se interessam pela construção de uma memória que construa cidadania. Posto que nenhum grupo sem memória é propriamente cidadão.

Àquelas monjazinhas do Barroco que não publicavam porque não podiam sequer chegar às instituições censórias do Estado, condenadas que estavam em suas clausuras a não conseguir contatarem-se com impressores, às poetas que excepcionalmente ultrapassaram esta barreira e tiveram a satisfação de tornar públicos alguns de seus textos no Antigo Regime, à extraordinária Sóror Mariana Alcoforado, quem nunca soube do rotundo êxito literário de suas Cartas Portuguesas escritas a seu sedutor francês que nunca as respondeu, mas deu-as à tradução para ufanar-se do amor que tinha inspirado em longes terras, à bravia paulista Teresa Margarida da Silva e Orta, que escreveu talvez o primeiro protorromance em português, Aventuras de Diófanes (1753) e que é apenas honrada em sua terra natal através do nome de um colégio na grande periferia paulistana, que não por ter sua obra inserida no cânone da literatura brasileira, à Marquesa de Alorna, D. Leonor de Almeida, vítima, como Teresa Margarida, de Pombal, e quem teve sua obra rasurada por seu próprio filho uma vez morta, mulher de letras cujos interessantes poemas poucos encontram tempo de ler e menos de ensinar e que por, isso mesmo, não fazem parte do banquete canônico, dedico, finalmente, o presente texto.

A memória é cidadania. Renovar o cânone é ampliá-la. Reler o deslido, arriscando novas desleituras que nem por isso devem ser temidas, daí relê-lo de novo e de novo deslê-lo como só quem releu o deslido pode ousar ou arrostar, é renovação, que não simples ampliação, e concomitante recriação de memória.

E porta que se abre para a cidadania.

Osasco, 8 de Dezembro de 2020 


\section{Cadernos de Literatura Comparada}

Fernan Díaz, quem teve que esperar 800 anos para se casar

\section{NOTAS}

* Horácio Costa ( São Paulo, 1954): poeta com 13 livros de poesia publicados no Brasil e 7 no exterior, traduzido a onze línguas. Prêmio Jabuti (2014) por Bernini. Doutorado em Yale (1994) com uma tese sobre José Saramago, foi professor titular na Universidade Nacional Autónoma do México e é professor livre-docente na faculdade de Letras da USP. Foi presidente (20062008) da Associação Brasileira de Estudos da Homocultura-ABEH.

${ }^{1}$ Cf. Cantigas d'escarnho e mal dizer - edição crítica e vocabulário M. Rodrigues Lapa, Lisboa, Edições João Sá da Costa, 1995. Pág. 70; indexado sob o número 80. Daqui para a frente, no presente texto indicarei as cantigas referentes a este livro pelos seus numerais, entre parêntesis, seguindo a prática de Rodrigues Lapa.

${ }^{2}$ Cf. Dicionário da literatura medieval galega e portuguesa - organização e coordenação de Giulia Lanciani e Giuseppe Tavani. Lisboa, Caminho, 1993; págs. 28-9, verbete: "Airas Perez Vuitoron”.

${ }^{3}$ Sigo a interpretação de Rodrigues Lapa na ed. acima mencionada (pág. 70, nota 6 aditada à cantiga 80, ora em estudo): "coita = empenho, pressa".

${ }^{4}$ Cf. https://en.wikipedia.org/wiki/Adelphopoiesis (Wikipédia em inglês, consultada em 7 de dezembro de 2020).

${ }^{5}$ Boswell, John, Same-Sex Unions in Pre-Modern Europe e Christianity, Social Sciences and Homosexuality - Gay People in Western Europe from the Beginning of the Christian Era to the Fourteenth Century. Respec. Nova Iorque, Random House, 1995 e The University of Chicago Press, 1981.

${ }^{6}$ Cf. https://gl.wikipedia.org/wiki/Adelphopoiesis (Wikipédia em galego; consultada em 6 de dezembro de 2020).

${ }^{7}$ Cit., pág. 70.

${ }^{8}$ Desenvolvi esse tema em "A tradição animada: sobre o escárnio, sobre o maldizer", in Literatura. Interfaces. Fronteiras, Org. Juciene Cavalheiro, Manaus, UEA Edições, 2010, pp. 123-141.

${ }_{9}$ Por exemplo, grupos de alunos e professores atualmente refrescam olhares sobre Camões, como o da Marcia Arruda Franco, na FFLCH-USP, e o liderado por Luis Maffei, na UFF. Mas há muito por fazer em relação a vários outros poetas canônicos, nos cenários díspares da língua portuguesa.

${ }^{10}$ Cf. Calamus - Male Homosexuality in Twentieth Century Literature - An International Anthology (1982). Ed. David Galloway e Christian Sabisch; Nova Iorque, Quill, 1982. Conto de Darcy Penteado (1926-1987), "The Ice-Cream Fairy" ("A bichinha sorveteira" ), de Theoremambo (1979), traduzido ao inglês por Barbara Shelby Morello, The Penguin Book of Homosexual Verse (1983): poema "Episode"("Episódio") de Cassiano Nunes (1921-2007) trad. ao inglês por E.A. Lacey. Obs.: este foi o tradutor de Bom Crioulo, de Adolfo Caminha (1890) ao inglês (Bom-Crioulo - The Black Man and the Cabin Boy; San Francisco, Gay Sunshine Press, 1982). Contém três textos introdutórios “Introduction", de Raul de Sá Barbosa, "Adolfo Caminha's Bom-Crioulo", do poeta norte-americano Robert Howes, e "Translator Preface", de E. A. Lacey. Uma das mais importantes traduções da literatura homoerótica brasileira ao inglês, que dá o seu devido lugar internacional a esse importante romance do século XIX, apesar do silenciamento crítico doméstico, tal e como enfoquei no ensaio "Surpresas do naturalismo luso-brasileiro: Bom-Crioulo, de Adolfo Caminha e O Barão de Lavos, de Abel Botelho", in Do inefável ao afável - ensaios sobre sexualidade, gênero e estudos queer, Manaus, UEA Edições, 2012, pp. 65-74.

${ }^{11}$ In Correia, Natália (seleção, prefácio e notas), Antologia de poesia portuguesa erótica e satírica, Lisboa, Antígona/Frenesi, 1999. Cit. à pág. 12.

12 "Quando Carolina Michaëlis de Vasconcelos se ocupou das cantigas satíricas dos nossos Cancioneiros medievais, sacrificando os preconceitos no altar da cultura, declarou que não evitaria as obscenidades que tão desafogadamente ocorrem no género burlesco dos Cancioneiros, sempre que estivesse em causa apurar a verdade. (...) Fazer nossas as palavras da corajosa 
investigadora é uma homenagem que o seu exemplo nos impõe, afrontando uma moral onde à feminilidade sempre coube observar a regra de uma discreção apetecida pelo idealismo patriarcal." (Correia 1999: 11).

${ }^{13}$ Cf. Lapa 1995: 6.

\section{Bibliografia}

Adelphopoiesis - https://en.wikipedia.org/wiki/Adelphopoiesis (Wikipédia em inglês, consultada em 7 de dezembro de 2020).

Boswell, John (1981), Same-Sex Unions in Pre-Modern Europe e Christianity, Social Sciences and Homosexuality - Gay People in Western Europe from the Beginning of the Christian Era to the Fourteenth Century. Respec. Nova Iorque, Random House, 1995 e The University of Chicago Press.

Cantigas d'escarnho e mal dizer - edição crítica e vocabulário M. Rodrigues Lapa. Lisboa, Edições João Sá da Costa, 1995.

Coote, Stephen (ed.) (1987), The Penguin Book of Homosexual Verse. Harmondsworth,Middlesex, England, New York, N.Y., U.S.A., Penguin Books.

Correia, Natália (org.) (1999), Antologia de poesia portuguesa erótica e satírica, Lisboa, Antígona/ Frenesi.

Costa, Horácio (2010), "A tradição animada: sobre o escárnio, sobre o maldizer", in Literatura. Interfaces, Fronteiras, Org. Juciene Cavalheiro, Manaus, UEA Edições, pp. 123-141.

- - (2012), "Surpresas do naturalismo luso-brasileiro: Bom-Crioulo, de Adolfo Caminha e O Barão de Lavos, de Abel Botelho", in Do inefável ao afável - ensaios sobre sexualidade, gênero e estudos queer, Manaus, UEA Edições, pp. 65-74.

Dicionário da literatura medieval galega e portuguesa - organização e coordenação de Giulia Lanciani e Giuseppe Tavani. Lisboa, Caminho, 1993; págs. 28-9, verbete: "Airas Perez Vuitoron".

Galloway, David / Sabisch, Christian (eds.) (1982), Calamus - Male Homosexuality in Twentieth Century Literature - An International Anthology, Ed. Nova Iorque, Quill. 